Gefässchirurgie 2016 · [Suppl 2]: 21:S63-S70 DOI 10.1007/s00772-016-0157-3

Published online: 3 August 2016

(c) The Author(s) 2016. This article is available at SpringerLink with Open Access

CrossMark

\author{
T. Schmitz-Rixen ${ }^{1} \cdot$ G. Torsello ${ }^{2} \cdot$ M. Steinbauer ${ }^{3} \cdot$ R. T. Grundmann ${ }^{4}$ \\ ${ }^{1}$ Klinik für Gefäß- und Endovascularchirurgie, Klinikum der Goethe-Universität, Frankfurt am Main, \\ Deutschland \\ ${ }^{2}$ Klinik für Vaskuläre und Endovaskuläre Chirurgie, Universitätsklinikum und St. Franziskus Hospital \\ Münster, Münster, Deutschland \\ ${ }^{3}$ Klinik für Gefäßchirurgie, Krankenhaus Barmherzige Brüder Regensburg, Regensburg, Deutschland \\ ${ }^{4}$ Deutsches Institut für Gefäßmedizinische Gesundheitsforschung gGmbH, Berlin, Deutschland
}

\title{
The endovascular performance spectrum of vascular surgery departments in Germany
}

\section{Results of an online survey among senior department physicians}

of abdominal aortic aneurysms (AAA). On the basis of the Medicare database (patients aged 67 years or older) for the period 2001-2008, Schermerhorn et al. [3] reported 128,598 patients who received elective treatment for AAA, 79,463 of whom underwent endovascular repair $(61.8 \%)$ and 49,135 open repair (OR). The percentage of endovascular procedures for the treatment of intact AAA (iAAA) has meanwhile continued to rise, totalling $72 \%$ in the German Institute for Vascular Medicine Healthcare Research [4] (Deutsches Institut für Gefäßmedizinische Gesundheitsforschung, DIGG) register for 2014. Diagnosis-related groups hospital statistics released by the German Federal Statistical Office (Statistisches Bundesamt) permit an overview of inpatient endovascular treatment in Germany [5]. - Table 1 provides some information on the procedures carried out in 2013. The statistics for 2013 also show 40,668 arteriograms of neck vessels, 77,140 of abdominal vessels, 138,860 of pelvic vessels, 159,990 of lower extremity vessels and 43,668 super-selective arteriograms, excluding coronary angiograms.

We conducted a survey to make a better assessment of the scope of services offered by vascular surgeons in Germany specifically in relation to endovascular treatment and the results of this survey are presented. At the same time, we have used the subject as an opportunity to provide an overview of the numbers reported for endovascular training in the literature.

\section{Methods}

Between 16 August and 23 October 2015 a total of 308 senior vascular surgeons were surveyed on departmental structure and scope of services using a 19-point questionnaire. To this end, more than $95 \%$ of all senior departmental heads of vascular surgical units in Germany gained access to an online questionnaire. By checking and blocking IP addresses once questionnaires had been completed, it was largely possible to make access selective and preclude the possibility of responding twice. Responses were received from 223 vascular surgeons in total, representing a response rate of $72 \%$. The following information on questions and answers relates to this collective. In all 216 out of 223 respondents $(96.8 \%)$ held the qualification of vascular surgeons and $189(84.8 \%)$ the qualification of surgeon (• Fig. 1). Of these $62.2 \%$ reported an additional qualification as a $\mathrm{DGG}^{\circledR}$ endovascular surgeon and $43.5 \%$ as a $\mathrm{DGG}^{\circledR}$ endovascular specialist. A total of $78.9 \%$ had gained specialist knowledge of interventional radiology, $72.6 \%$ of radiology and $10.7 \%$ of
The German version of this article can be found under doi:10.1007/s00772-016-0123-0. 
Table 1 Endovascular procedures in German hospitals in 2013 (Source: German Federal Statistical Office 2014)

\begin{tabular}{lll}
\hline Procedure & $\begin{array}{l}\text { German op- } \\
\text { eration and } \\
\text { procedure code }\end{array}$ & Number (n) \\
\hline $\begin{array}{l}\text { Percutaneous transluminal vascular intervention, extracra- } \\
\text { nial internal carotid artery }\end{array}$ & $8-836.0 \mathrm{k}$ & 2427 \\
\hline $\begin{array}{l}\text { Percutaneous transluminal vascular intervention, extracra- } \\
\text { nial internal carotid artery and common carotid artery }\end{array}$ & $8-836.0 \mathrm{~m}$ & 2611 \\
\hline Abdominal aorta & & \\
\hline $\begin{array}{l}\text { Bifurcation graft, aorto-bi-iliac without fenestration or side } \\
\text { branch }\end{array}$ & $5-38 \mathrm{a} .14$ & 7082 \\
\hline Tubular graft, iliac without sidearm & $5-38 \mathrm{a} .40$ & 1812 \\
\hline Tubular graft, aortic without fenestration or sidearm & $5-38 \mathrm{a} .1 \mathrm{e}$ & 809 \\
\hline Open surgical angioplasty (balloon) & & \\
\hline Other abdominal and pelvic vessels & $5-38 f .9$ & 3783 \\
\hline Open surgical angioplasty: femoral vessels & $5-38 f . b$ & 5107 \\
\hline Open surgical angioplasty: lower leg vessels & $5-38 f . c$ & 2318 \\
\hline Percutaneous transluminal vascular interventions & & \\
\hline PTA: other abdominal and pelvic vessels & $8-836.09$ & 28,489 \\
\hline PTA: visceral vessels & $8-836.0 \mathrm{a}$ & 3747 \\
\hline PTA: femoral vessels & $8-836.0 \mathrm{~b}$ & 67,048 \\
\hline PTA: lower leg vessels & $8-836.0 \mathrm{c}$ & 38,792 \\
\hline PTA percur & & \\
\hline
\end{tabular}

PTA percutaneous transluminal angioplasty

Table 3 Annual number of procedures performed

\begin{tabular}{|llll}
\hline Response options & $\begin{array}{l}\text { Average num- } \\
\text { ber per re- } \\
\text { sponding } \\
\text { department }\end{array}$ & $\begin{array}{l}\text { Total } \\
\text { number } \\
(\boldsymbol{n})\end{array}$ & $\begin{array}{l}\text { Number of } \\
\text { respondents }\end{array}$ \\
\hline Diagnostic angiograms & 166 & 32,575 & 196 \\
\hline Percutaneous arterial interventions & 259 & 51,078 & 197 \\
\hline Percutaneous interventions on deep veins & 9 & 1557 & 173 \\
\hline $\begin{array}{l}\text { Percutaneous interventions on the superficial } \\
\text { venous system }\end{array}$ & 45 & 7254 & 160 \\
\hline Hybrid arterial procedures & 141 & 30,988 & 220 \\
\hline Hybrid venous procedures & 8 & 1295 & 160 \\
\hline Interventions on dialysis shunts & 35 & 7080 & 204 \\
\hline Interventions for vascular malformations & 5 & 717 & 149 \\
\hline Others & 24 & 844 & 35 \\
\hline
\end{tabular}

computed tomography (CT) radiology. Of the respondents $30(13.5 \%)$ worked in university hospitals, 39 (17.5\%) in maximum care institutions, 83 (37.2\%) in specialized care institutions, 64 (28.7\%) in basic and standard care institutions, $5(2.2 \%)$ in specialist hospitals, 1 in an external physician department, and 1 in private practice.

In terms of departmental structure, $171(76.7 \%)$ specified a vascular surgery department, $47(21.1 \%)$ a unit within
Table 2 Technical facilities in vascular

surgery departments

Response options Number of \% responses

(n)

\begin{tabular}{lll}
\hline C-arm & $135 / 223$ & 60.5 \\
\hline $\begin{array}{l}\text { C-arm with flat } \\
\text { detector }\end{array}$ & $99 / 223$ & 44.4 \\
\hline Hybrid procedure & $75 / 223$ & 33.6 \\
\hline $\begin{array}{l}\text { Mini-hybrid proce- } \\
\text { dure }\end{array}$ & $10 / 223$ & 4.5 \\
\hline Angio-suite & $91 / 223$ & 40.8 \\
\hline
\end{tabular}

Table 4 The 10 procedures most fre-

quently reported by US vascular surgeons

applying for recertification examination in

1995 vs. 2009 (adapted from Eidt et al. [14])

\begin{tabular}{|c|c|c|}
\hline Rank & 1995 & 2009 \\
\hline 1 & Leg bypass (all) & Arteriogram \\
\hline 2 & CEA & Varicose vein \\
\hline 3 & AV graft & PTA \\
\hline 4 & AAA (open) & Stent \\
\hline 5 & Thrombectomy & Leg bypass (all) \\
\hline 6 & Varicose vein & AV fistula \\
\hline 7 & $\begin{array}{l}\text { Digit amputa- } \\
\text { tion }\end{array}$ & CEA \\
\hline 8 & $\begin{array}{l}\text { Below-knee } \\
\text { amputation }\end{array}$ & Venogram \\
\hline 9 & AV fistula & IVC filter \\
\hline 10 & IVC filter & EVAR \\
\hline \multicolumn{3}{|c|}{$\begin{array}{l}\text { CEA - carotid endarterectomy, } A V \text { - arte- } \\
\text { riovenous, } P T A-\text { percutaneous translumi- } \\
\text { nal angioplasty, } A A A-\text { abdominal aortic } \\
\text { aneurysm, } I V C \text { - inferior vena cava, EVAR - } \\
\text { endovascular aortic repair } \\
\text { The average number of cases submitted by } \\
\text { applicants in } 1995 \text { was } 183 \text { and } 647 \text { in } 2009\end{array}$} \\
\hline
\end{tabular}

cal facilities available in the surveyed departments.

\section{Results}

Scope of endovascular activities: diagnosis $(2.2 \%)$ a unit within a cardiac surgery department. The number of staff per department was reported to include on average one chief physician, three senior physicians, one specialist vascular surgeon with no official position and three assistant physicians. Of the centers surveyed $57 \%$ had no certification, $24 \%$ were certified by the DGG alone, $12 \%$ had triple certification and $7 \%$ double certification. - Table 2 lists the techni-
In terms of diagnosis a distinction was made in the questionnaire between angiography, shuntography and diagnostic phlebography. Of the 223 respondents 187 (83.9\%) reported performing diagnostic angiography, 176 (79.9\%) shuntography and 85 (38.1\%) diagnostic phlebography. 
Gefässchirurgie 2016 • [Suppl 2]: 21:S63-S70 DOI 10.1007/s00772-016-0157-3

(c) The Author(s) 2016. This article is available at SpringerLink with Open Access

\section{T. Schmitz-Rixen · G. Torsello · M. Steinbauer · R. T. Grundmann}

\section{The endovascular performance spectrum of vascular surgery departments in Germany. Results of an online survey among senior department physicians}

Abstract

Aim. To survey the scope of vascular surgery services in Germany.

Method. A total of 308 senior German vascular surgeons received a 19-point questionnaire pertaining to department structure and scope of services. Of these surgeons 223 replied between 16 August 2015 and 23 October 2015 (response rate $72 \%$ ), with $62.2 \%$ reporting an additional qualification as an endovascular surgeon according to the guidelines of the German Society for Vascular Surgery and Vascular Medicine (Deutsche Gesellschaft für Gefäßchirurgie und Gefäßmedizin, DGG) and $43.5 \%$ as a $\mathrm{DGG}^{\circledR}$ endovascular specialist. Results. The number of respondents fully authorized to train in vascular surgery was $71.3 \%$, while $28.3 \%$ were authorized for limited training. Authorization as a $\mathrm{DGG}^{\circledR}$ endovascular surgeon was reported by $24.2 \%$ and authorization as a DGG ${ }^{\circledR}$ endovascular specialist by $17 \%$ of respondents. All respondents performed endovascular interventions on pelvic vessels and $99.1 \%$ also reported carrying out femoral and popliteal endovascular interventions. Endovascular procedures in crural vessels were carried out by $90.1 \%$ and $93.7 \%$ of vascular surgeons performed endovascular procedures in the region of the abdominal aorta (segment $\mathrm{V}$ ), arteriovenous (AV) fistulas and shunts (85.2\%), upper extremity vessels $(80.3 \%)$, the thoracic aorta (segment III, 68.2\%), renal arteries (62.8\%) and visceral aorta (segment IV, $60.5 \%$ ). In all $43.5 \%$ of respondents reported experience with endovascular procedures on the carotid bifurcation. Percutaneous arterial procedures formed the focus of endovascular activity, totalling on average 259 interventions per year and department, followed by diagnostic angiography (without intervention) at 166 procedures per year and hybrid arterial interventions at 141 interventions per year. Conclusion. This survey revealed a high leve of endovascular expertise among vascular surgeons in Germany. This applies not only to the scope of endovascular activities in diagnosis and treatment but also to the number of estimated annual procedures.

Keywords

Vascular surgery · Endovascular surgery Specialist $\cdot$ Training $\cdot$ Survey

\section{Das endovaskuläre Leistungsspektrum deutscher gefäßchirurgischer Abteilungen. Ergebnis einer Online-Umfrage unter leitenden Abteilungsärzten}

\section{Zusammenfassung}

Zielsetzung. In einer Umfrage sollte das Leistungsspektrum der deutschen Gefäßchirurgie ermittelt werden.

Methodik. In der Zeit vom 16. August 2015 bis 23. Oktober 2015 wurden insgesamt 308 leitende Gefäßchirurgen zu ihrer Abteilungsstruktur und ihrem Leistungsspektrum anhand von 19 Punkten befragt. Geantwortet haben 223 (Beantwortungsquote $72 \%$ ). Eine Zusatzqualifikation Endovasculärer Chirurg $D G G^{\circledR}$ nannten $62,2 \%$, eine Qualifikation Endovasculärer Spezialist DGG ${ }^{\circledR} 43,5 \%$. Ergebnisse. Insgesamt 71,3\% gaben eine volle Ermächtigung zur Weiterbildung in der Gefäßchirurgie an, 28,3 \% eine Ermächtigung zur Teil-Weiterbildung Gefäßchirurgie. Eine Ermächtigung zum endovaskulären Chirurgen DGG ${ }^{\circledR}$ meldeten $24,2 \%$, eine solche zum endovaskulären Spezialisten DGG ${ }^{\circledR} 17 \%$ der Antwortenden. Alle Antwortenden berichteten, an Beckengefäßen und 99,1 \% an Oberschenkelstrombahn und A. poplitea endovaskulär therapeutisch tätig zu sein, an den Unterschenkelgefäßen waren es 90,1 \%. Sehr hoch war auch der Prozentsatz an Gefäßchirurgen, die im Bereich der abdominellen Aorta (Abschnitt V; 93,7\%), an AV-Fisteln und Shunts $(85,2 \%)$, Armgefäßen $(80,3 \%)$, thorakaler Aorta (Abschnitt III; 68,2\%), Nierenarterien $(62,8 \%)$ und viszeraler Aorta (Abschnitt IV; 60,5\%) endovaskuläre Eingriffe vornahmen. Erfahrung mit endovaskulären Eingriffen an der Karotisgabel nannten 43,5\% der Antwortenden. Den Schwerpunkt der endovaskulären Tätigkeit machten perkutane Interventionen an den Arterien aus, von denen durchschnittlich 259 Eingriffe pro Jahr und Abteilung vorgenommen wurden. Es folgten die diagnostischen Angiographien (ohne Intervention) mit 166 jährlichen Prozeduren und Hybrideingriffe an den Arterien mit 141 jährlichen Interventionen.

Folgerung. Unsere Umfrage zeigt die hohe Kompetenz der Gefäßchirurgen bei endovaskulären Eingriffen in Deutschland. Dies gilt sowohl für den Umfang der endovaskulären Tätigkeit in Diagnostik und Therapie als auch die Zahl der geschätzten jährlich durchgeführten Eingriffe.

Schlüsselwörter

Gefäßchirurgie · Endovaskuläre Chirurgie · Spezialist · Training $\cdot$ Erhebung

\section{Scope of endovascular treatment activities}

- Fig. 2 shows the scope of endovascular treatment activities in detail. All respondents reported performing endovascular interventions on pelvic vessels, $99.1 \%$ on femoral and popliteal arteries and $90.1 \%$ on crural vessels. A high percentage of vascular surgeons performed endovascu- lar interventions in the abdominal aortic region (segment $\mathrm{V}, 93.7 \%$ ), arteriovenous (AV) fistulas and shunts (85.2\%), upper extremity vessels $(80.3 \%)$, the thoracic aorta (segment III, 68.2\%), renal arteries $(62.8 \%)$ and the visceral aorta (segment IV, 60.5\%). Of the respondents $43.5 \%$ reported experience with endovascular procedures on the carotid bifurcation. Only experiences with vas- cular malformations $(30.5 \%$ of respondents) and endovascular intracranial procedures $(8.5 \%)$ were reported comparatively rarely. When asked whether endovascular procedures involved hybrid or percutaneous approaches $99.1 \%$ reported performing hybrid and $71.3 \%$ percutaneous interventions. 


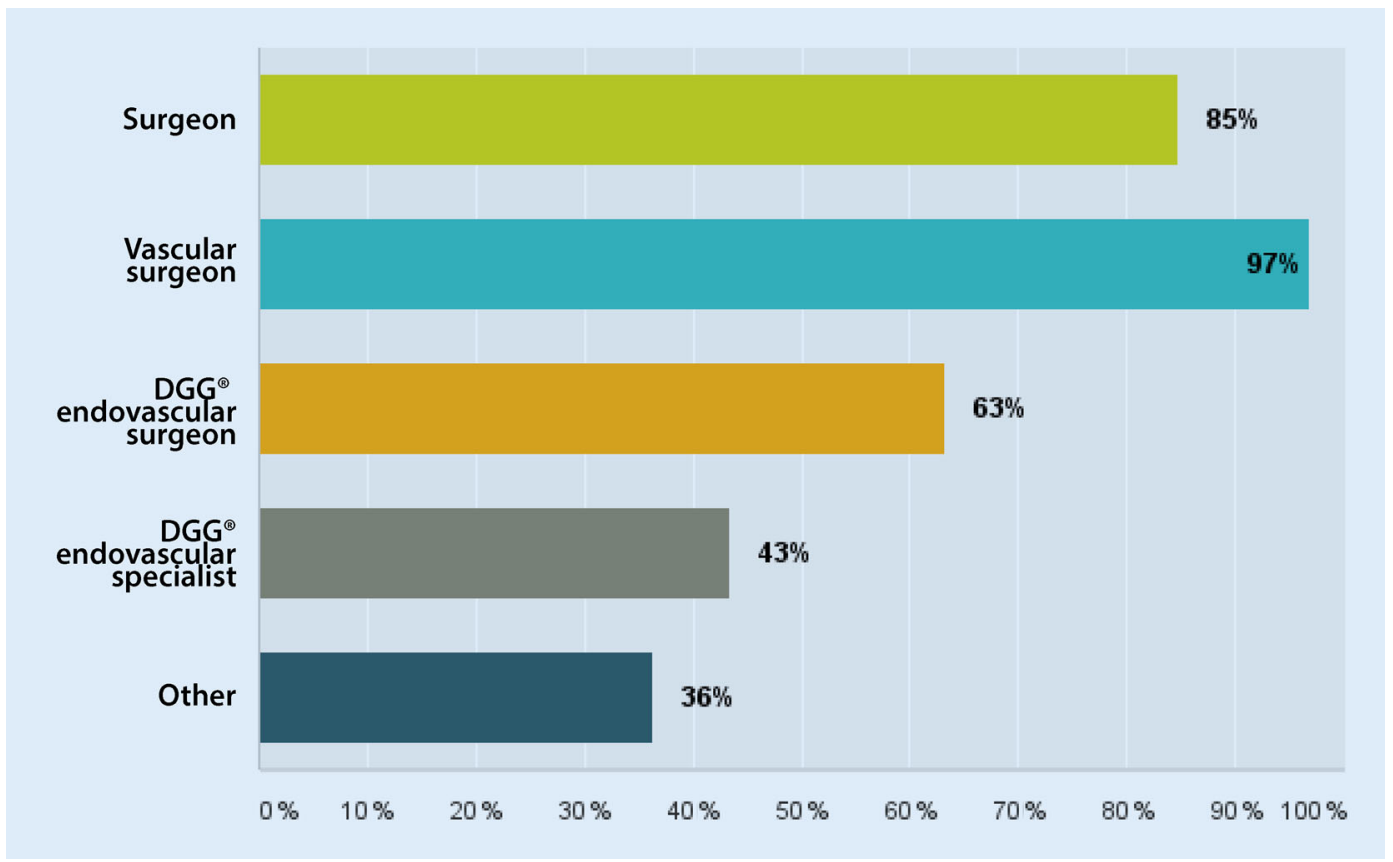

Fig. $1 \varangle$ Further training status among senior physicians

\section{Reported number of annual endovascular interventions}

The reported numbers of procedures performed annually per department (based either on figures for 2014 or projected figures for 2015) are given in • Table 3. Percutaneous arterial interventions represented the main focus of endovascular activities, with 259 interventions performed on average per year and per responding department. These were followed by diagnostic angiograms (without intervention) at 166 procedures per year and hybrid arterial interventions at 141 interventions per year.

\section{Departments performing activities}

\section{Diagnostic angiography}

The questionnaire asked which department in the hospital most commonly performed diagnostic angiography. Of the respondents $14.4 \%$ reported that $51-75 \%$ of diagnostic angiograms were performed in the radiology department, a further $34 \%$ reported corresponding percentages of $76-99 \%$ and $29.4 \%$ stated that all diagnostic angiograms were performed in the radiology department. A total of $14.6 \%$ respondents stated that all diagnostic angiograms were performed in the vascular surgical unit. In contrast, $17.4 \%$ stated that no diagnostic angiograms were performed in the vascular surgical unit, while a further $45.5 \%$ put the percentage of vascular surgical unit-based diagnostic angiograms as a percentage of all diagnostic angiograms at $1-25 \%$.

\section{Percutaneous arterial procedures}

The percentage of percutaneous arterial interventions performed in the radiology department was put at $51-75 \%$ by $16.7 \%$ of respondents, at $76-99 \%$ by $27.4 \%$, and at $100 \%$ by $15.5 \%$. A total of $14.5 \%$ reported that no percutaneous arterial interventions were performed in the radiology department (• Fig. 3).

With regard to vascular surgical departments, $8.3 \%$ reported percentages of $76-99 \%$ and $23.3 \%$ a percentage of $100 \%$. In contrast, $8.2 \%$ stated that no percutaneous arterial interventions were performed in vascular surgical departments, while $40.9 \%$ gave corresponding percentages of 1-25\%. Percutaneous arterial interventions were relatively rare in angiology and cardiology departments. For example, $58.7 \%$ stated that no interventions were performed in the angiology department at their institution. In contrast, only $7.8 \%$ and $6.1 \%$ reported that $76-99 \%$ or indeed all of percutaneous arterial interventions were performed in angiology departments. Altogether, $75.5 \%$ reported that no percu- taneous arterial interventions were performed in cardiology departments. Only $3 \%$ put the proportion of percutaneous arterial interventions performed in cardiology departments at 76-99\%.

\section{Percutaneous venous procedures}

In total, $43.9 \%$ reported that all venous percutaneous procedures were performed in vascular surgical departments, while $7.3 \%$ put this at $76-99 \%$. That no venous procedures were performed in the vascular surgical department was reported by $23.1 \%$, while a further $10.9 \%$ put this at $1-25 \%$. Comparative figures for radiology departments were as follows: $33.1 \%$ reported that all percutaneous venous procedures were performed in radiology departments, while $9 \%$ put this at $76-99 \%$. In all, $32.4 \%$ reported that no venous procedures were performed in radiology departments and $11 \%$ that 1-25\% were performed. With regard to angiology departments, $78.6 \%$ stated that no percutaneous venous procedures were performed here and the corresponding figure for cardiology departments was $95.5 \%$.

\section{Procedures for malformations}

More than $75 \%$ of malformations were treated exclusively in vascular surgical 


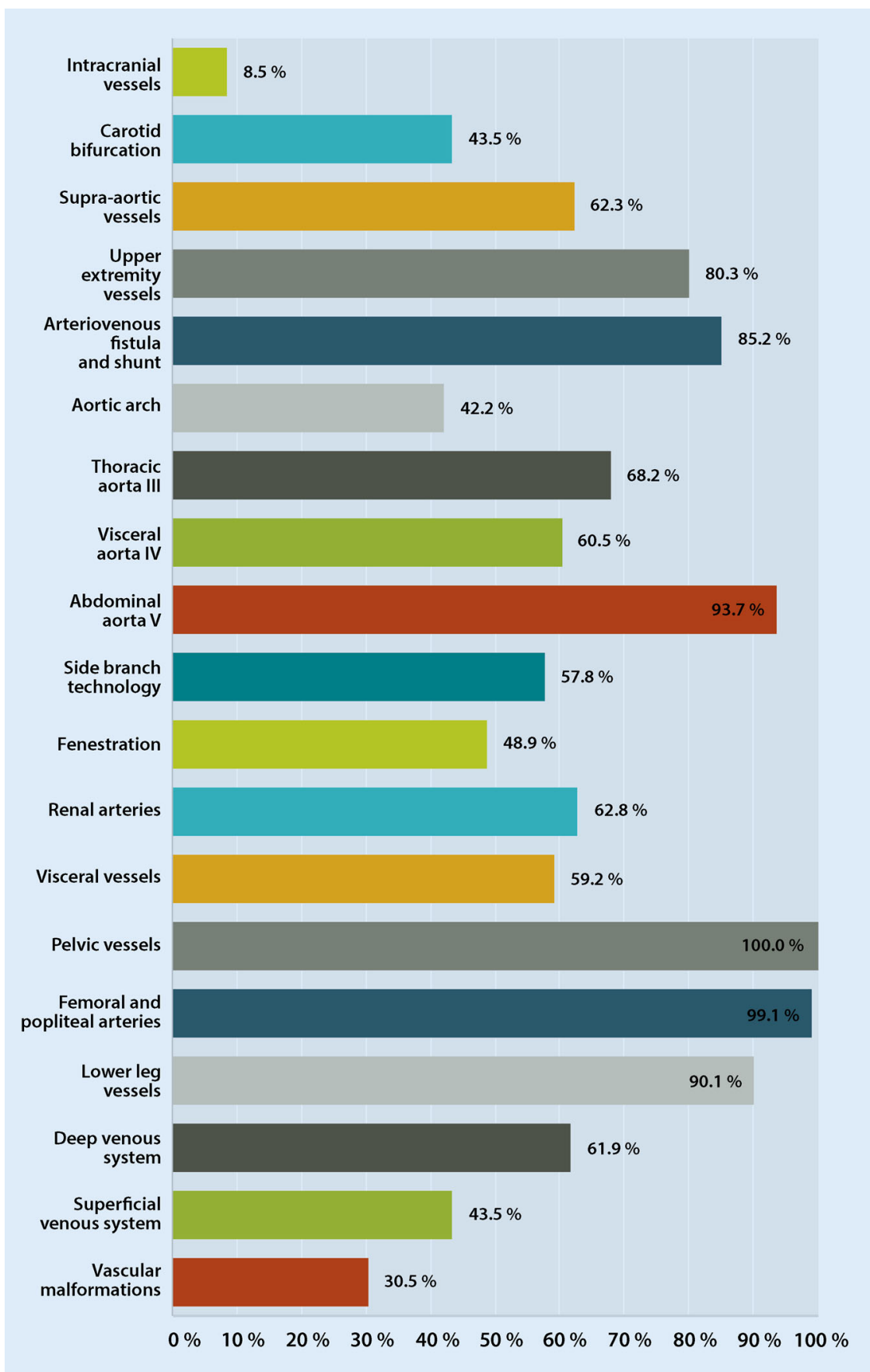

Fig. $2 \Delta$ Scope of endovascular treatment activities

departments, the remainder primarily in radiology departments.

\section{Endovascular component of the hybrid procedure}

Respondents were asked who performed the endovascular component of hybrid procedures. In $75 \%$ of departments, this person was solely the vascular surgeon and in other $25 \%$ by the radiologist. Altogether, $58.9 \%$ of radiologists, $89.7 \%$ of
At total of $71.3 \%$ of respondents were fully authorized to provide vascular surgical training and $28.3 \%$ to provide angiologists and $98.8 \%$ of cardiologists in the departments surveyed had no indures (• Fig. 4).

\section{Authorization to provide further training}

limited training. Authorization to provide training to $\mathrm{DGG}^{\circledR}$ endovascular surgeon level was reported by $24.2 \%$ and to $\mathrm{DGG}^{\circledast}$ endovascular specialist level by $17 \%$ of respondents. Further training in endovascular techniques was provided by vascular surgeons in $96.8 \%$ of the departments surveyed, radiologists in $36.3 \%$, angiologists in $9 \%$, and cardiologists in $2.2 \%$.

\section{Guest students}

Respondents were also asked whether their departments had capacity to supervise the further training of guest students and if yes, how many guest students and for what period of time? Altogether, 95 departments were able to take guest students for 1 month, 78 for 3 months, 43 for 6 months and 64 for over 6 months. Thus, at least 104 guest students could be supervised for 1 month, 88 for 3 months, 51 for 6 months, and 88 for even longer than 6 months.

\section{Discussion}

The results of the survey revealed a high level of endovascular expertise among vascular surgeons in Germany. This applied not only to the scope of endovascular activities in diagnosis and treatment but also to the number of estimated annual procedures. Nowadays, experience in endovascular techniques is required of all vascular surgeons working in western countries [6]. In a survey of members of the Society for Vascular Surgery (SVS) conducted by Matthews et al. [7], $37.8 \%$ of respondents reported that endovascular procedures accounted for $51-75 \%$ of the case volume. Of these respondents, $20 \%$ estimated that they performed open procedures as frequently as endovascular procedures and only $20 \%$ reported that endovascular interventions accounted for less than $25 \%$ of the activities. As many as $12 \%$ of respondents stated that endovascular procedures accounted for even more than $75 \%$ of the case volume. An age dependence was seen in this survey: $89.9 \%$ of younger vascular surgeons (aged below 50 years) reported that endovascular procedures made up half of the workload, while this proportion was reported by 


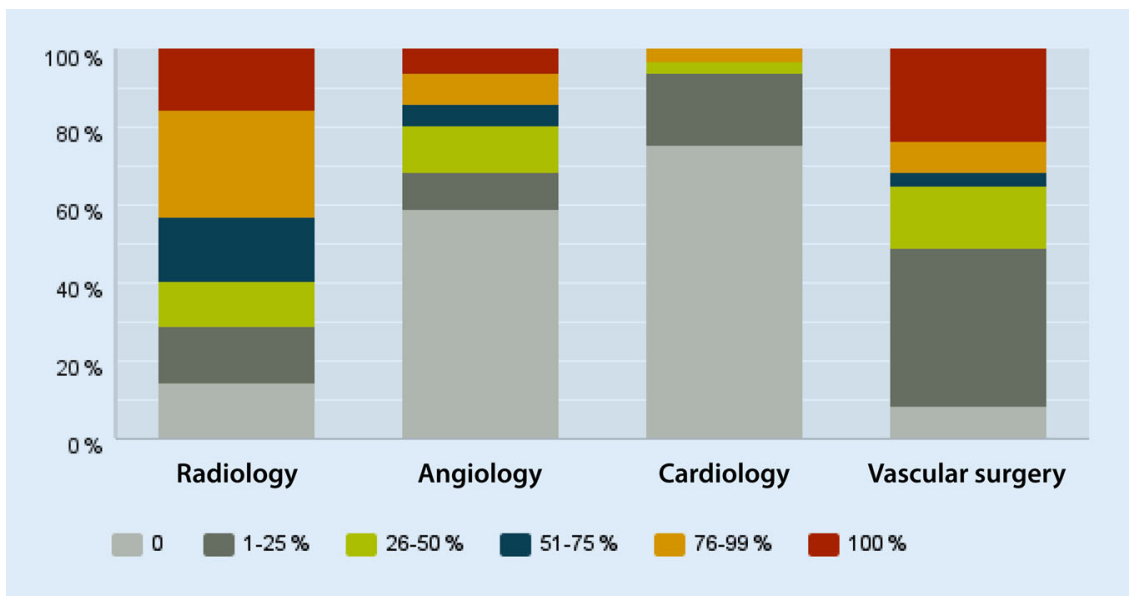

Fig. $3 \Delta$ Percentage share of the various departments of the total volume of percutaneous arterial interventions

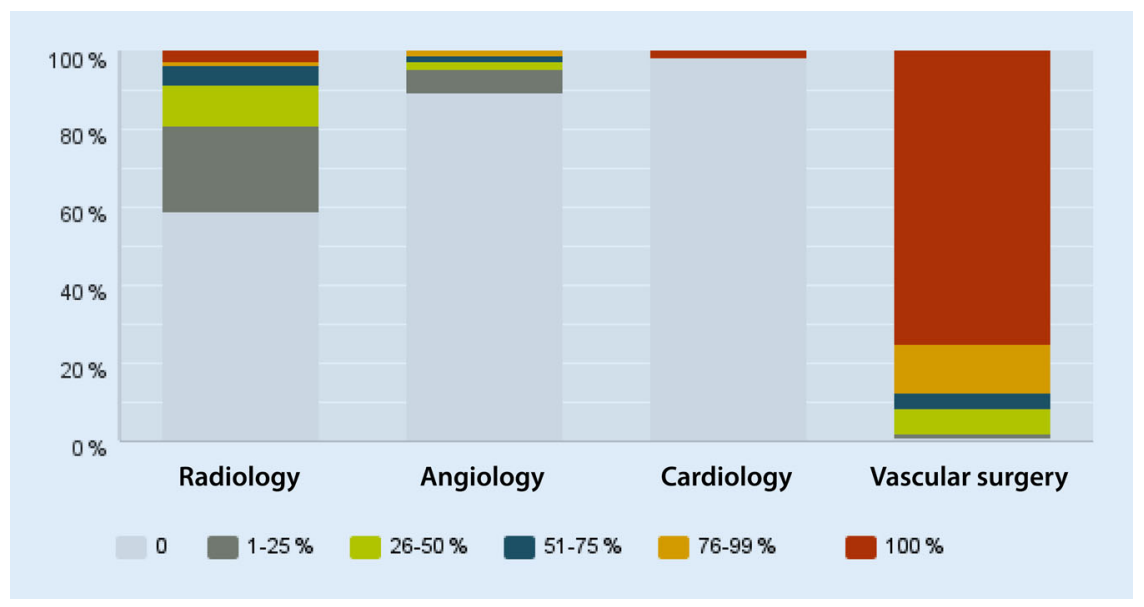

Fig. $4 \Delta$ Percentage share of the various departments of the total volume of hybrid procedures

only $62 \%$ of vascular surgeons aged over 50 years. Harkin et al. [8] surveyed 450 vascular surgeons in the UK on their activities and 352 surgeons responded (78\% response rate). Over $90 \%$ of vascular surgeons performed the index operations open aneurysm repair, carotid endarterectomy, infrainguinal bypass and amputation, while $84 \%$ performed standard endovascular aortic repair (EVAR). More complex endovascular procedures, such as thoracic EVAR (TEVAR, 39\%), fenestrated EVAR (35\%) and branched EVAR (24\%) were performed less frequently. Peripheral angioplasty belonged to the repertoire of $31 \%$ of vascular surgeons. Only $20 \%$ of surgeons performed complex open thoracoabdominal aortic surgery and $43 \%$ renal access surgery. The lower density of vascular surgeons in the UK (7 surgeons per 1 million pop- ulation at the time of the survey) needs to be taken into account in the description of this field of activity.

Endovascular interventions in the lower extremities are performed by a number of different specialists. Wallace et al. [9] analyzed routine data from the Florida Agency for Health Care Administration including 15,398 hospitalized patients between 2005 and 2009 not undergoing concomitant surgical procedures. The percentage of procedures performed by vascular surgeons from all endovascular interventions rose steadily during this period from $28 \%$ to $48 \%$ in 2009 , while the percentage of interventional cardiologists dropped from $47 \%$ to $33 \%$ and interventional radiologists from $25 \%$ to $20 \%$; however, as the majority of these interventions are performed in an outpatient setting in the USA, the quota of individual disciplines in relation to the total case volume should be estimated with caution. A study conducted by Harris et al. [10] based on data from the Centers for Medicare \& Medicaid Services (CMS) in the USA is potentially better suited to this end. The CMS database contained all procedure-related invoices for this patient population (patients over 65 years). According to this study, growth was seen in all disciplines (i.e. radiology, cardiology and vascular surgery) for the code 37205 (transcatheter placement of an intravascular stent in a vessel, excluding coronary, carotid and vertebral arteries) between 2000 and 2007, the highest growth being seen in vascular surgery; however, the percentage performed by vascular surgeons was still smaller than those performed by radiologists and cardiologists. Calculated on the basis of 100,000 Medicare insurees, vascular surgeons performed 54 of these interventions in 2007, cardiologists 95 and radiologists 67 . The highest growth in vascular surgery was also registered for the code 75962 (transluminal balloon angioplasty, peripheral arteries), whereby the percentage performed by vascular surgeons went on to exceed that of radiologists: looking at a population of 100,000 Medicare insurees, 64 of these interventions were carried out by vascular surgeons, 78 by cardiologists and 58 by radiologists in 2007 .

The study by Wallace et al. [9] highlighted that vascular surgeons dealt with the more serious cases, treating $50 \%$ of all patients with CLI, while interventional cardiologists, in contrast, treated $57 \%$ of all patients with IC. This confirms the results of an earlier study by Vogel et al. [11] who analyzed a total of 1887 percutaneous transluminal angioplasty (PTA) on lower extremities, 1021 performed by vascular surgeons and 866 by cardiologists. Here again, the vascular surgical patients were significantly more severely diseased. The percentage of patients with IC in the vascular surgical patient population was $60.7 \%$ but $80.7 \%$ in the cardiology population. In contrast, patients with at resting pain accounted for $16.0 \%$ of vascular surgical patients and gangrene patients for $23.3 \%$. The 
corresponding figures for cardiologists were $6.2 \%$ and $13.1 \%$. Vogel et al. [11] also calculated the cost of resources under North American billing conditions. According to their calculation, treatment in vascular surgical departments was significantly more cost-effective than in cardiology departments but with comparable outcomes. Reasons for this included the fact that vascular surgeons utilized fewer resources and hence worked more cost-effectively compared with cardiologists (in terms of the number of catheters used and technical equipment/medical supplies/number of consultations). Particularly with regard to EVAR for AAA, the leading expertise of the vascular surgeon is undisputed. This was demonstrated by an analysis of the NIS in the USA for the period 2001-2009 that included 28,094 EVAR procedures, $97 \%$ of which were for non-ruptured AAA [12]. In this collective, $92.2 \%$ of all EVAR procedures were performed by surgeons (not further differentiated) and $7.8 \%$ by interventionalists (also not further differentiated). Patients treated by surgeons exhibited lower hospital mortality $(2.0 \%$ vs. $4.3 \%)$ and, as a gauge for complications, shorter average hospital stays (3.69 vs. 5.88 days); however, this benefit for surgery did not reach clinical significance when only therapists with large case volumes were compared.

\section{Further endovascular training}

A survey conducted by Dalsing et al. [13] of vascular surgery residents in training demonstrated where the focus of interest lies among trainee vascular surgeons in the USA today: the teaching faculty and endovascular facilities were the most important factors in their ranking of a training program, with $68.8 \%$ and $60 \%$, respectively, rating these as very important. These were followed by case volumes in open aortic surgery (43.8\%), open carotid surgery $(40.0 \%)$ and thoracic aortic interventions $(37.6 \%)$ in the ranking of importance for the choice of training program. Residents were also asked about their levels of competence (self-grading) and graded own endovascular competence as high with $78.1 \%$ who considered themselves very compe- tent in general endovascular techniques and $68.8 \%$ in EVAR and TEVAR; however, only $38.7 \%$ considered themselves highly competent in carotid stenting and familiarity with lytic therapy was also lower at $56.3 \%$. The number who graded themselves as very competent in carotid endarterectomy (CEA) was $78.1 \%$, in lower extremity revascularization $71.9 \%$ and in open abdominal aortic surgery $46.9 \%$. How the scope of vascular surgical practice has changed in recent decades was strikingly demonstrated by a comparison of the 10 most common procedures reported by applicants for the vascular surgery recertification examination in the USA in 1995 vs. 2009 ([14]; - Table 4).

In 2010 Fitridge et al. [15] proposed an international core curriculum for endovascular surgical training, which set 100 diagnostic angiograms, 50 angioplasties/stents (20 aortoiliac, 15 femoral above-knee popliteal and 15 infragenicular), as well as 20 EVAR as the minimal requirements for specialist recognition. Can a trainee vascular surgeon achieve this case log on a 1-2 year training program and where does the focus lie? Schanzer et al. [16] sought answers to these questions and according to their analysis, open procedures accounted for approximately $48 \%$, diagnostic endovascular procedures $20 \%$ and therapeutic endovascular procedures $32 \%$ of the 519 major vascular surgical procedures performed on average by graduating trainees in 2007. Approximately 50 EVAR were set against 41 open aortic procedures, $42 \mathrm{CEA}$, and 36 open peripheral bypasses, to mention the most common. Schanzer et al. [16] found a significant increase in the mean number of procedures performed by trainees between 2001 and 2007, from 298 to 519, attributable almost entirely to the substantially increased case volume in 2007 compared with 2001. Parallel to this increase in endovascular procedures, only $65 \%$ of trainee vascular surgeons questioned in another US survey believed that they would leave their training program with competence levels that prepared them well for open vascular surgery in their future practice, whereas $84 \%$ felt confident that they could provide the full range of endovascular surgical procedures [17].

With their survey Reed et al. [18] set out to ascertain the extent to which vascular surgical departments in the USA have the capacity to adequately train vascular surgery resident trainees in interventional techniques. In all 191 out of 240 trainees who had been trained in 91 hospitals with special training programs responded. In 2008 it was possible to learn interventional techniques largely (over $80 \%$ ) in vascular surgical institutions, most commonly with EVAR (99\%), suprainguinal $(94.8 \%)$ and infrainguinal (92.7\%) PTA/stenting and least commonly with carotid artery stenting (CAS, $82.2 \%$ ). Trainees additionally received training in interventional techniques in cardiology (more rarely) and interventional radiology (more frequently). When asked about the percentage accounted for by the individual departments in terms of their training in interventional techniques, $38.5 \%$ of respondents estimated that $75-100 \%$ of their training had been obtained in the vascular surgical department, $30.8 \%$ put this figure at $51-75 \%$ and a further $30.8 \%$ at 26-50\%. A UK survey of 217 trainee vascular surgeons, of which 153 (71\%) responded, painted a very different picture [19]. At the time of the survey 80 of these 153 (52\%) were working in posts that offered no endovascular training and $88 \%$ $(123 / 153)$ had performed less than 10 peripheral angiograms and/or angioplasties with or without supervision in the previous 12 months. A total of $63 \%(96 / 153)$ reported that they had never performed a procedure of this kind. The majority of trainees (104/153) had performed less thatn10 EVAR (partially or completely, with or without supervision) in the previous 12 months. Furthermore, no experience with endovenous laser therapy, radiofrequency ablation or foam sclerotherapy for varicose vein treatment was reported by $33 \%, 49 \%$, and $46 \%$, respectively. This survey demonstrates, in terms of individual vascular surgical department capacity to offer further training, the range of endovascular services available and the opportunities offered to endovascular guest students, among other factors that at least endovascular train- 
ing opportunities in Germany for trainee vascular surgeons in vascular surgical departments are significantly broader. Finally, a further and particular aspect of endovascular activity requires mention, i. e. radiation exposure. Kirkwood et al. [20] showed that providing surgeons with training in techniques aimed at reducing radiation exposure during endovascular procedures is an important factor in reducing radiation doses in the interventional context. In our survey $72.6 \%$ of respondents reported having specialist knowledge of radiology, while $78.9 \%$ reported specialist knowledge of interventional radiology. To what extent these rates can be improved on remains open.

\section{Conclusion}

- At a response rate of $72 \%$, the present survey can be considered representative.

- The data show high levels of competence in endovascular procedures among vascular surgeons in Germany.

- This applies not only to the scope of diagnostic and therapeutic endovascular activities but also to the number of estimated annual procedures performed.

\section{Corresponding address}

\section{Prof. Dr. T. Schmitz-Rixen}

Klinik für Gefäß- und Endovascularchirurgie, Klinikum der Goethe-Universität Theodor-Stern-Kai-7, 60590 Frankfurt am Main, Deutschland

schmitz-rixen@em.uni-frankfurt.de

Acknowledgements. We would like to thank Dr. M. Jacobs, managing director of the DGG, for logistical support during the survey.

\section{Compliance with ethical guidelines}

Conflict of interest. T. Schmitz-Rixen, G. Torsello, M. Steinbauer and R.T. Grundmann declare that they have no competing interests.

The accompanying manuscript does not include any studies on humans or animals performed by any of the authors.
The supplement containing this article is not sponsored by industry.

Open Access. This article is distributed under the terms of the Creative Commons Attribution 4.0 International License (http://creativecommons.org/ licenses/by/4.0/), which permits unrestricted use, dis tribution, and reproduction in any medium, provided you give appropriate credit to the original author(s) and the source, provide a link to the Creative Commons license, and indicate if changes were made.

\section{References}

1. Sachs T, Pomposelli F, Hamdan A, Wyers M, Schermerhorn M (2011) Trends in the national outcomes and costs for claudication and limb threatening ischemia: angioplasty vs bypass graft. JVasc Surg 54:1021-1031.e1

2. Bisdas T, Borowski M, Torsello G, First-Line Treatments in Patients With Critical Limb Ischemia (CRITISCH) Collaborators (2015) Current practice of first-line treatment strategies in patients with critical limb ischemia. JVasc Surg 62:965-973

3. Schermerhorn ML, Buck DB, O'Malley AJ, Curran T, McCallum JC, Darling J, Landon BE (2015) Longterm outcomes of abdominal aortic aneurysm in the Medicare population. $\mathrm{N}$ Engl J Med 373:328-338

4. Grundmann RT (2015) Versorgung des abdominellen Aortenaneurysmas (AAA) 2014. Registerbericht desDIGG derDGG. Gefässchirurgie 20:376-384

5. Statistisches Bundesamt (2014) Fallpauschalenbezogene Krankenhausstatistik (DRG-Statistik). Operationen und Prozeduren der vollstationären Patientinnen und Patienten in Krankenhäusern bis zum kodierbaren Endpunkt 2013. Statistisches Bundesamt, Wiesbaden

6. Choke E, Sayers R (2015) Viewpoint: adaptation of vascular surgery in the interventional era. Heart 101:342-345

7. Matthews MA, Satiani B, Lohr JM (2013) Trends in a changing vascular practice environment for members of the Society for Vascular Surgery. J Vasc Surg 57:586-592

8. Harkin DW, Beard JD, Shearman CP, Wyatt MG (2015) The vascular surgery workforce: a survey of consultant vascular surgeons in the UK, 2014. Eur J Vasc Endovasc Surg 49:448-454

9. Wallace JR, YuoT, Marone L, ChaerRA, Makaroun MS (2014) Outcomes of endovascular lower extremity interventions depend more on indication than physician specialty. JVasc Surg 59:376-383

10. Harris TJ, Zafar AM, Murphy TP (2011) Utilization of lower extremity arterial disease diagnostic and revascularization procedures in Medicare beneficiaries 2000-2007. AJR Am J Roentgenol 197:W314-317

11. Vogel TR, Dombrovskiy VY, Carson JL, Haser PB, Graham AM (2009) Lower extremity angioplasty: impact of practitioner specialty and volume on practice patterns and healthcare resource utilization. JVasc Surg 50:1320-1324

12. McCutcheon BA, Talamini MA, Chang DC, Rose JA, Bandyk DF, Wilson SE (2013) The comparative effectiveness of surgeons over interventionalists in endovascular repairs of abdominal aortic aneurysm. Ann Surg 258:476-482

13. Dalsing MC, Makaroun MS, Harris LM, Mills JL, Eidt J, Eckert GJ (2012) Association of Program Directors in Vascular Surgery (APDVS) survey of program selection, knowledge acquisition, and education provided as viewed by vascular trainees from two different training paradigms. J Vasc Surg 55:588-597

14. Eidt JF, Mills J, Rhodes RS, Biester T, Gahtan V, Jordan WD, Hodgson KJ, Kent KC, Ricotta JJ, Sidawy AN, Valentine J (2011) Comparison of surgical operative experience of trainees and practicing vascular surgeons: a report from the Vascular Surgery Board of the American Board of Surgery. JVasc Surg 53:1130-1139 (discussion 1139-1140)

15. Fitridge R, Quigley F, Vicaretti M (2010) Should we develop a core international curriculum for Vascular and Endovascular Surgery? Eur J Vasc Endovasc Surg 39(Suppl 1):S10-S14

16. Schanzer A, Steppacher R, Eslami M, Arous E, Messina L, Belkin M (2009) Vascular surgery training trends from 2001-2007: A substantial increase in total procedure volume is driven by escalating endovascular procedure volume and stable open procedure volume. J Vasc Surg 49:1339-1344

17. Duran C, Bismuth J, Mitchell E (2013) A nationwide survey of vascular surgery trainees reveals trends in operative experience, confidence, and attitudes about simulation. JVasc Surg 58:524-528

18. Reed AB, Rhodes R, Ricotta J (2010) Determining whotrains vascular surgery fellows in endovascular techniques. JVasc Surg 51:756-759

19. Karthikesalingam A, Buxton $P$, Marron C, Oshin OA, Scurr JR, Wall M, Rouleaux Club (2012) Deficiencies persist in the experience of UK vascular trainees: a survey of Rouleaux Club members. Vasc Endovascular Surg 46:358-363

20. Kirkwood ML, Arbique GM, Guild JB, Timaran C, Chung J, Anderson JA, Valentine RJ (2013) Surgeon education decreases radiation dose in complex endovascular procedures and improves patient safety. J Vasc Surg 58:715-721 